\title{
THE ACCESSIBILITY ASSESSMENT OF REGIONAL TRANSPORT NETWORK IN THE SOUTH EAST EUROPE
}

\author{
Ana Šimecki ${ }^{1}$, Sanja Steiner ${ }^{2}$, Olja Čokorilo ${ }^{3}$ \\ ${ }^{1}$ South East Europe Transport Observatory, Omladinskih Brigada 1, 11198 Belgrade, Serbia \\ ${ }^{2}$ University of Zagreb, Faculty of Traffic and Transport Science, Vukelićeva 4, 10000 Zagreb, Croatia \\ ${ }^{3}$ University of Belgrade, Faculty of Transport and Traffic Engineering, Vojvode Stepe 305, 11000 \\ Belgrade, Serbia
}

Received 22 May 2013; accepted 5 September 2013

\begin{abstract}
Development of transport infrastructure and establishment of effective transport systems is a prerequisite for the achievement of broad based economic growth which is one of the European and Southeast European major development goals. Due to the lack of intraregional connectivity within the South East Europe (SEE), certain parts of the region have limited access to regional, European and global markets. Mentioned imbalance of accessibility to services, markets and opportunities for further social and economic progress is an obstacle for overall development of the SEE region. The research is thematically oriented on the assessment of road, rail and air passenger transport accessibility in the SEE with the aim of providing scientific overview of current regional transport network connectivity serving as basis for further identification of potential improvement measures. The research is conducted on the SEETO Comprehensive Network that was established as a main output of joint cooperation between seven Regional Participants and the European Commission as a result of signing of the Memorandum of Understanding for the Development of the Core Regional Transport Network (MoU) in 2004. The multimodal Core Regional Transport Network defined under the MoU represents a commonly agreed main and ancillary transport infrastructure in the SEE, which is the base for the implementation of transport related investments programmes.
\end{abstract}

Keywords: transport, accessibility, connectivity, SEETO Comprehensive Network.

\section{Introduction}

The post war development of transport infrastructure in the SEE at the beginning of the last decade was tightly connected to the national links without a comprehensive regional view. However, in the process of economic development of each country within the region, the need for intraregional accessibility in all aspects became even more important. On the other hand, constant pressure from the European Union (EU) towards the integration of the region and the establishment of political, territorial and economic cohesion became the one of the preconditions for the EU accession process. The EU accession processes have a significant impact on the transport development in the SEE as the EU candidate and potential EU candidate countries need to transpose EU body law into each individual system. Croatia became a full EU Member in 2013 where long transition period is likely to be slow downing, but for other candidate

\footnotetext{
${ }^{1}$ Corresponding author: asimecki@seetoint.org
} 
(Former Yugoslav Republic of Macedonia and Montenegro) and potential candidate countries the process will be accelerated in the forthcoming period.

Furthermore, progress in transport, economic and social regional development is highly dependent on a support of adequate transport infrastructure and the knowledge of its usage in a most efficient way. Accordingly, development of transport infrastructure became an explicit point of attention for Regional Participants (RP) to strengthen its economic and social cohesion as well as to reduce the disparities in levels of transport infrastructure development between them and the EU Member States.

To put a regional cooperation on a higher legally binding level, seven Regional Participants (Albania, Bosnia and
Herzegovina, Croatia, the Former Yugoslav Republic of Macedonia, Montenegro, Serbia and Kosovo) and the European Commission signed the MoU for the Development of the Core Regional Transport Network in 2004. The SEETO Comprehensive Network defined under the MoU represents a commonly agreed main and ancillary transport infrastructure in the SEE, which is the base for the implementation of transport related investment programmes.

The SEETO Comprehensive Network consists of $6,554 \mathrm{~km}$ of roads, $4,807 \mathrm{~km}$ of rails, 17 airports, 4 rivers, 8 inland waterway ports and 10 seaports (Fig. 1). The Network fosters development of the most efficient and environmentally friendly transport modes to improve transport connections with the TEN-T Network and to promote and enhance common transport policies in the SEE.

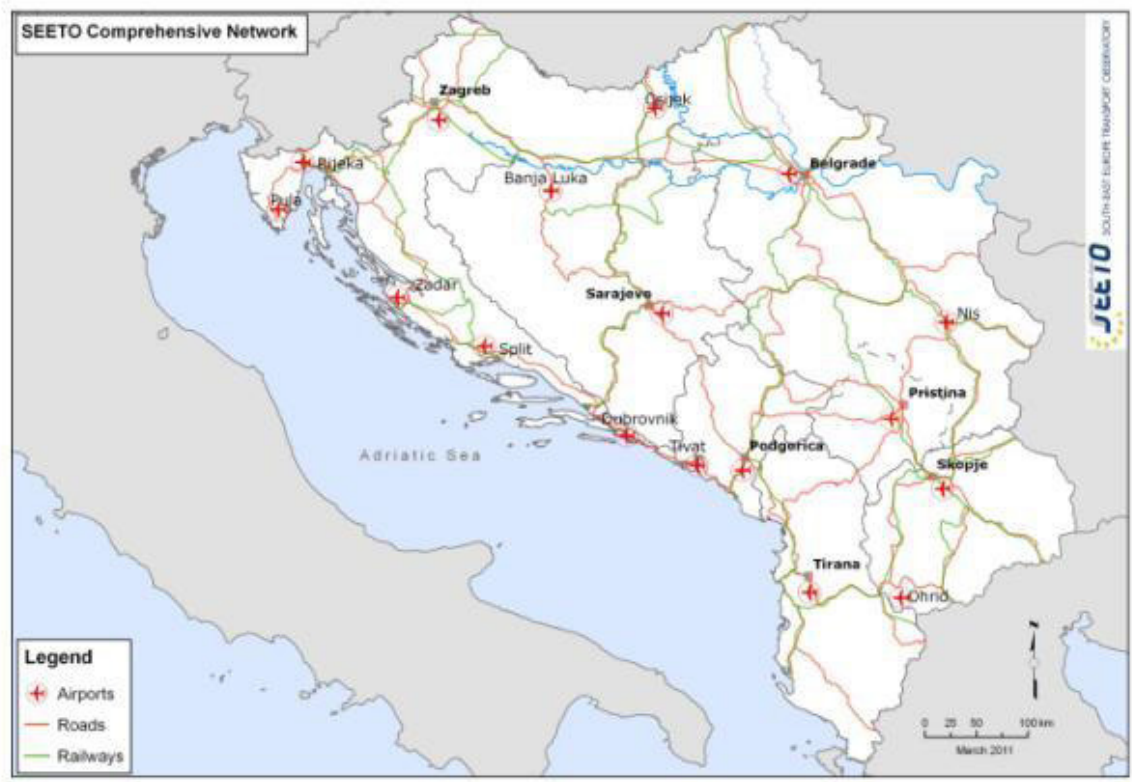

Fig. 1.

SEETO Comprehensive Network

Source: South East Europe Transport Information System (SEETIS) III 
In 2011, as a part of TEN-T policy review, the SEETO Comprehensive Network, which is a precursor of the TEN-T Comprehensive Network in the SEE, was included in the TEN-T network maps as indicative. Following the inclusion, the importance of transport infrastructure development in the SEE became even more important as it became apparent on the EU transport maps to all external parties. Nevertheless, in spite all efforts and progress made in the last eight years, the infrastructure is still underdeveloped and high investments are needed for its improvement. Such underdevelopment of infrastructure, together with overburdening border crossing procedures evident in existing 14 external and 38 internal road and rail border crossing points along the SEETO Road Comprehensive Network seriously hinders the passenger and trade transport within the region.

Passenger transport accessibility assessment on road, rail and air connections among the SEETO Comprehensive Network airports is presented together with detail evaluation of each transport mode in particular through description of networks infrastructure, traffic and investment terms. Data on the SEETO Comprehensive Road and Rail Network infrastructure, traffic and investments as well as on SEETO Comprehensive Network airport has been collected through the South East Europe Transport Information System (SEETIS) III database for the year 2010 which is a referent year for all presented analysis.

\section{Accessibility Assessment of the SEETO Comprehensive Network}

\subsection{Accessibility Assessment of the SEETO Comprehensive Road Network}

Road infrastructure is a prominent mean of connecting people in the SEE. Intraregional movements are tightly connected to the SEETO Comprehensive Road Network which is a single layer network composed of $2,987 \mathrm{~km}$ of Corridors and $3,567 \mathrm{~km}$ of Routes. It is an extension of the TEN-T Comprehensive Road Network in the SEE and is a backbone of passenger transport within the region. The network provides connections with 10 seaports, 17 airports and five inland waterway ports within the $\mathrm{SCN}$. As it is the only transport mode within the region which ensures connections to landlocked and peripheral areas, it has been a focus of transport development since its establishment in 2004.

In the period 2004-2010, €6.4 billion were invested in completed projects on the SEETO Comprehensive Road Network and $€ 3.5$ billion are being implemented in ongoing projects, what makes $83 \%$ of total completed and ongoing investments in all transport modes in the mentioned period. In spite of high investments in the road network infrastructure in the SEE region, the condition of the network with $33 \%$ of motorways in 2010 is beyond European standards (Nikolić et al., 2008).

Road congestions have direct impact on traffic flows, travel times and overall accessibility within the region. In 2010, the LoS C and higher were reported on 5,609 $\mathrm{km}$ of the SEETO Comprehensive Road Network, while congested sections with restricted speed (LoS D to LoS F) were recorded on $954 \mathrm{~km}$ (14\% of the network) showing increasing trend in $2010(954 \mathrm{~km})$ from $2009(561 \mathrm{~km})$ despite the highest investments in road sector. Impact of congested sections on the network directly impacts travel time due to reduced travel speed which is crucial factor in passengers transport (Fig. 2). 


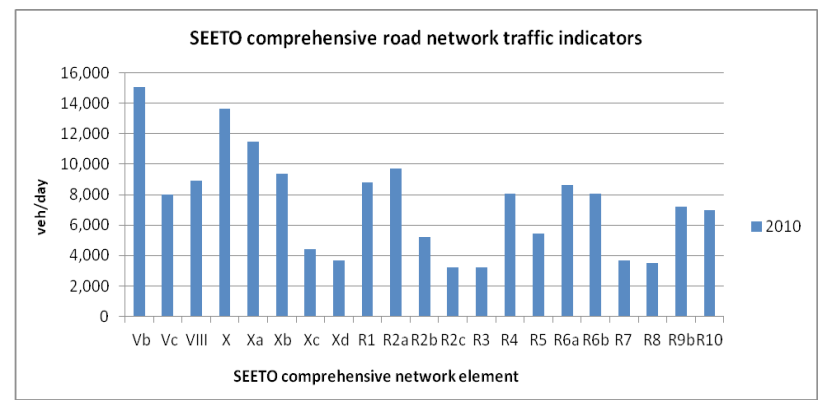

Fig. 2.

SEETO Comprehensive Road Network Traffic Indicators

Source: South East Europe Transport Information System (SEETIS) III

In the SEE, 17 road connections have travel distance higher than $800 \mathrm{~km}$ and 11 connections higher than $1,000 \mathrm{~km}$ which does not serve for passenger road transport. Out of mentioned 28 connections, air transport services are offered on two (2010) - one scheduled (Zagreb-Skopje) and one seasonal scheduled (Dubrovnik-Belgrade). Distance length varies significantly across the region from $89 \mathrm{~km}$ (Podgorica-Tivat) up to the longest distance of $1,492 \mathrm{~km}$ (TiranaPula). Average road network distance between airports is $550 \mathrm{~km}$ what provides basis for the establishment of air transport connections and thereby replacing the road transport mode considering the fact that most people preferred to drive than fly on journeys of $300 \mathrm{~km}$ or less, with cost and convenience being major factors.

Out of 136 road connections, 23 connections that are connecting Croatian and Serbian SCN airports are in a motorway standard above $90 \%$ while other Regional Participants have lower network standard (Fig. 3). Maximum allowed speed on those connections average is $120 \mathrm{~km} / \mathrm{h}$, which makes basic conditions for efficient and effective passenger road transportation. By comparing two individual connections with the same distance and different percentage of road infrastructure in a motorway standard it is evident that at the distance of $800 \mathrm{~km}$ and above the difference in travel time is doubled.

Fig. 3.

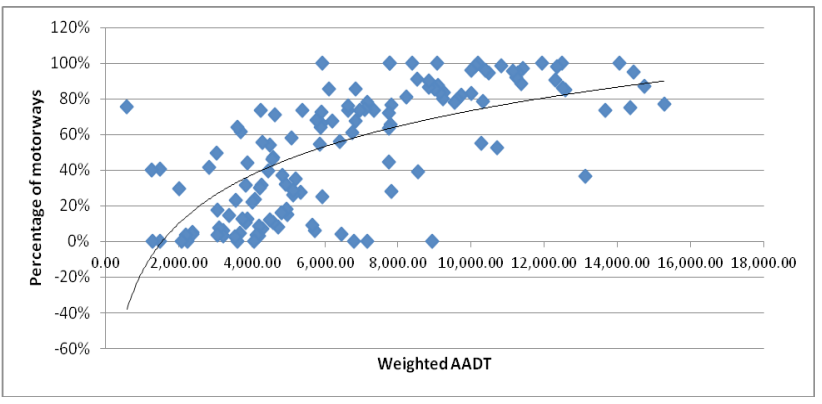

Correlation of Weighted AADT and Condition of Road Network Infrastructure Source: South East Europe Transport Information System (SEETIS) III 


\subsection{Accessibility Assessment of the SEETO Comprehensive Rail Network}

Main rail connections within the SEE region as well as with the TEN-T Network are forming the SEETO Comprehensive Rail Network in a total length of 4,807 $\mathrm{km}$ out of which $2,911 \mathrm{~km}$ are classified as Corridors and $1,896 \mathrm{~km}$ as Routes even though there are no differences in the importance among them. In the displacement of the rail network per Regional Participants the same pattern as in road network is perceivable showing that more than $60 \%$ of the network is placed in
Croatia and Serbia, while Montenegro and Kosovo accounts the smallest part.

Standard UIC ${ }^{2}$ methodology has been applied on calculation of the SEETO Comprehensive Network capacity. Additional indicator of SEETO Comprehensive Rail Network effectiveness are the bottlenecks evident on 144 $\mathrm{km}$ of Corridor $\mathrm{X}, 84 \mathrm{~km}$ occurred on single line sections and $60 \mathrm{~km}$ on double line sections. Low utilization pattern is detected on the SEETO Comprehensive Rail Network (below 50\%) as in the SCN airports displaying opposite trend than the one persistent on major European airports and the TEN-T railway lines (Table 1).

Table 1

SEETO Comprehensive Rail Network Passengers Traffic 2008-2010

\begin{tabular}{|c|c|c|c|c|}
\hline \multirow{2}{*}{ Corridor or Route } & \multicolumn{3}{|c|}{ Passenger traffic volume (million Pkm) } & \multirow{2}{*}{ Index 2010/2009 } \\
\hline & 2008 & 2009 & 2010 & \\
\hline Corridor $\mathrm{Vb}$ & 246 & 262 & 246 & 94 \\
\hline Corridor Vc & 123 & 118 & 118 & 100 \\
\hline Corridor VIII & 45 & 42 & 34 & 81 \\
\hline Corridor X & 1,263 & 1,642 & 1,527 & 93 \\
\hline Corridor $\mathrm{Xb}$ & 106 & 86 & 82 & 95 \\
\hline Corridor Xc & 1 & 1 & 1 & 100 \\
\hline Corridor Xd & 34 & 36 & 61 & 169 \\
\hline Route 1 & 68 & 75 & 71 & 95 \\
\hline Route 2 & 18 & 18 & 9 & 50 \\
\hline Route 4 & 289 & 191 & 213 & 112 \\
\hline Route 9a & 20 & 20 & 15 & 75 \\
\hline Route 9b & - & 1 & 1 & 100 \\
\hline Route 10 & 64 & 61 & 61 & 100 \\
\hline Route 11 & 6 & 3 & 6 & 200 \\
\hline Route 12 & - & 21 & 20 & 95 \\
\hline Route 13 & - & - & & - \\
\hline
\end{tabular}

Source: South East Europe Transport Information System (SEETIS) III

${ }^{2}$ UIC - Union internationale des chemins de fer. Analyses were done according to the standard UIC methodology, where capacity has been measured in trains per day through theoretical standard capacities based on track characteristics and UIC CODE 406 
Underdevelopment of rail infrastructure is a result of low investments in 2005-2010 period, amounting $€ 433.84$ million out of which $58 \%$ are already implemented, and $42 \%$ are still in the process of implementation. As presented in the highest investments were made in Croatia in the rehabilitation of rail infrastructure (49\%), followed by Serbia (40\%), while Macedonia and Montenegro had lower part (11\%). It can be concluded that in spite of promotion of rail transport at European level, the investments in SEETO Comprehensive Rail Network are $72 \%$ lower that investments in road network in 2005-2010 period and accordingly the overall condition of the rail network in the SEE has a decreasing trend reaching current unsatisfactory condition for efficient functioning of railway system in the SEE.

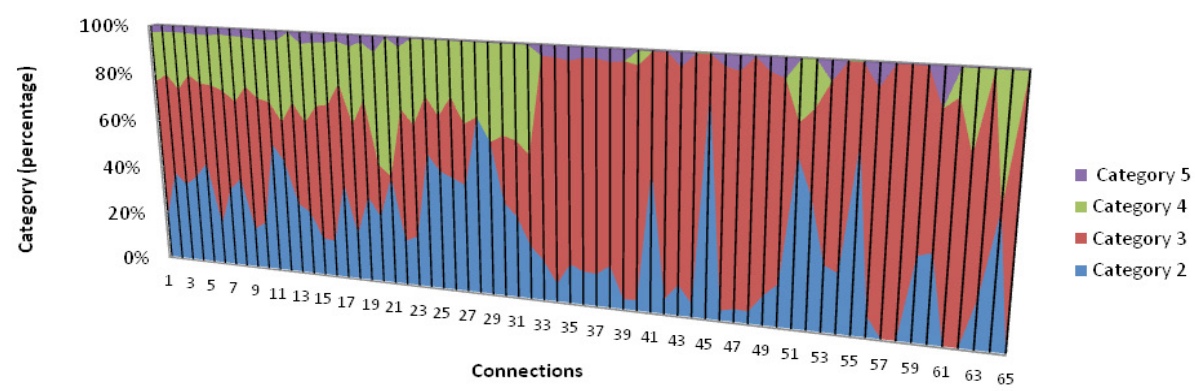

Fig. 4.

Condition Rail Network Connections among SCN Airports

Source: South East Europe Transport Information System (SEETIS) III

By observing condition of rail infrastructure per each individual connection it is perceivable that average rail connection is marked as $17 \%$ in Good, $54 \%$ in Medium, $16 \%$ in Poor and $3 \%$ in Very Poor condition (Fig. 4). Non existence of 'very good' as well as $17 \%$ of 'good' condition, which are preconditions for efficient functioning of the system and its competitiveness with other transport modes supports the foresaid fact that rail infrastructure standards in the SEE region are below European standards (Monsalve, 2011). Condition of the network directly defines average speed for passenger trains which amount $48 \mathrm{~km}$ /hour and it is the main factor of influence on performed travel time.
Due to underinvestment in the rail network and its current infrastructure condition which implicates reduced operating speed, previously elaborated distance levels acceptable for passenger transport should be lowered when applied on the SEE region.

The reason for that are high travel times which do not serve for passenger transport in the region where on travel distances of more than $400 \mathrm{~km}$ the competitive edge of conventional railways is rapidly declining influenced by road infrastructure development and lowering road travel times (Fig. 5). 


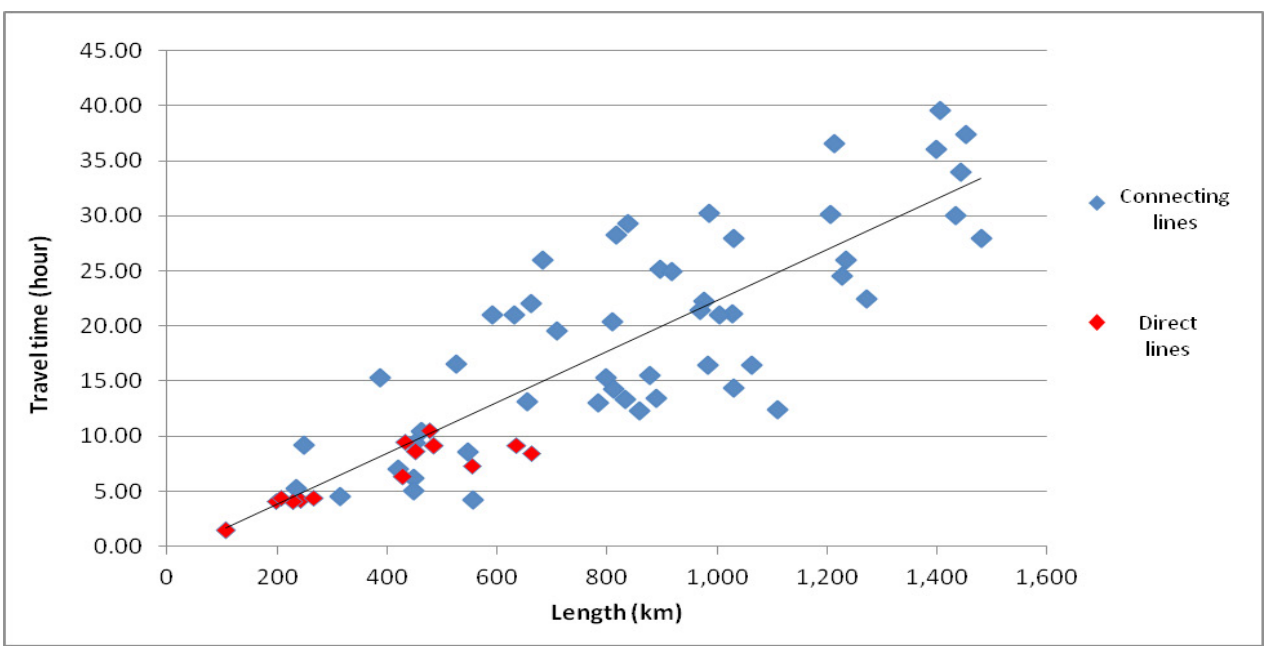

Fig. 5.

Ratio of Travel Time and Distance on Rail Connections among the SCN Airports Source: South East Europe Transport Information System (SEETIS) III

Travel time for each connection is derived as a function of distance and allowed speed with integrated average border crossings waiting time ( 20 minutes) on the international SEETO Comprehensive Rail Network connections as well as terminal (transfer) times on connecting lines. Average travel time on all rail connections among SCN airports is 18 hours while if only direct connections are considered the average travel time is 3 times lower.

\subsection{Accessibility Assessment of the SEETO Comprehensive Network Airports}

The existing connectivity network and air transport frequencies within the SEE region are bellow growing needs and demands of the travelling public. While connections with main European destinations are dominant and all leading European air carriers already operate in the SEE region, presently only
$10 \%$ of all SEE airlines commercial activities are realised within the SEE network. Therefore, an underdeveloped connection between individual capitals and major cities of the SEE region represents a barrier for fast and convenient travel within the region (Šimecki et al., 2011; Steiner et al., 2010a).

Key determinants of air transport connections development are based on contracts for the joint operations of air carriers and associated partners within airline alliances. Star Alliance, with Austrian Airlines, Lufthansa, Croatia Airlines and Adria Airways as members, dominates in the SEE area (Mantecchini et al., 2013). Accordingly, the highest frequency air transport connections in the SEE are linking the SEE and Western Europe, with the largest number of flights to European nodal airports (Frankfurt, Munich and Vienna) (Table 2). 
Table 2

Number of Available Destinations from the SCN Airports

\begin{tabular}{|c|c|c|c|c|c|c|c|c|c|c|c|c|}
\hline \multirow[t]{2}{*}{ Airport } & \multicolumn{11}{|c|}{ Year } & \multirow{2}{*}{$\begin{array}{c}\text { Percentage of } \\
\text { intraregional } \\
\text { destinations } \\
(2010)\end{array}$} \\
\hline & 2000 & 2001 & 2002 & 2003 & 2004 & 2005 & 2006 & 2007 & 2008 & 2009 & 2010 & \\
\hline Banja Luka & 3 & 4 & 3 & 2 & 1 & - & - & - & 3 & 3 & - & - \\
\hline Belgrade & 42 & 37 & 41 & 40 & 43 & 41 & 40 & 40 & 43 & 44 & 48 & $10,42 \%$ \\
\hline Dubrovnik & 10 & 12 & 17 & 22 & 20 & 26 & 31 & 34 & 37 & 44 & 49 & $6,12 \%$ \\
\hline Nis & - & - & - & - & 4 & 1 & 1 & 2 & 2 & 2 & 2 & $50,00 \%$ \\
\hline Ohrid & 8 & 4 & 4 & 4 & 4 & 5 & 5 & 7 & 5 & 4 & 2 & $50,00 \%$ \\
\hline Osijek & 1 & 1 & 3 & 2 & 2 & 2 & 3 & 2 & 3 & 3 & 4 & $50,00 \%$ \\
\hline Podgorica & 1 & 7 & 6 & 8 & 9 & 9 & 9 & 9 & 12 & 10 & 17 & $29,41 \%$ \\
\hline Pristina & 4 & 4 & 14 & 11 & 12 & 14 & 11 & 12 & 16 & 23 & 24 & $12,50 \%$ \\
\hline Pula & 3 & 6 & 7 & 6 & 5 & 7 & 11 & 10 & 12 & 16 & 20 & $10,00 \%$ \\
\hline Rijeka & 2 & 2 & 2 & 2 & 2 & 4 & 9 & 10 & 7 & 11 & 6 & - \\
\hline Sarajevo & 12 & 12 & 20 & 15 & 8 & 11 & 9 & 9 & 17 & 14 & 15 & $13,33 \%$ \\
\hline Skopje & 25 & 23 & 18 & 16 & 17 & 16 & 18 & 18 & 18 & 13 & 12 & $33,33 \%$ \\
\hline Split & 18 & 16 & 21 & 22 & 23 & 27 & 28 & 31 & 40 & 43 & 50 & $6,00 \%$ \\
\hline Tirana & 17 & 15 & 14 & 14 & 16 & 25 & 28 & 32 & 33 & 35 & 35 & $2,86 \%$ \\
\hline Tivat & 4 & 10 & 11 & 9 & 10 & 9 & 10 & 8 & 9 & 14 & 11 & $9,09 \%$ \\
\hline Zadar & 4 & 5 & 4 & 5 & 7 & 7 & 6 & 8 & 10 & 14 & 22 & $9,09 \%$ \\
\hline Zagreb & 28 & 29 & 28 & 25 & 26 & 30 & 33 & 34 & 39 & 36 & 34 & $23,53 \%$ \\
\hline
\end{tabular}

Source: Official Airline Guide (OAG) Database

In 2010, 18 air transport connections were operable making $13 \%$ out of possible connections in the SEE (136). Zagreb Airport was serving highest number of individual intra-regional connections (8) followed by Belgrade Airport (4). It should be noted that there is no existing connection between two major airports - Belgrade and Zagreb - in the SEE that possibly underpins economic development of those two countries especially in terms of potential business flights demand (Steiner et al., 2010b).

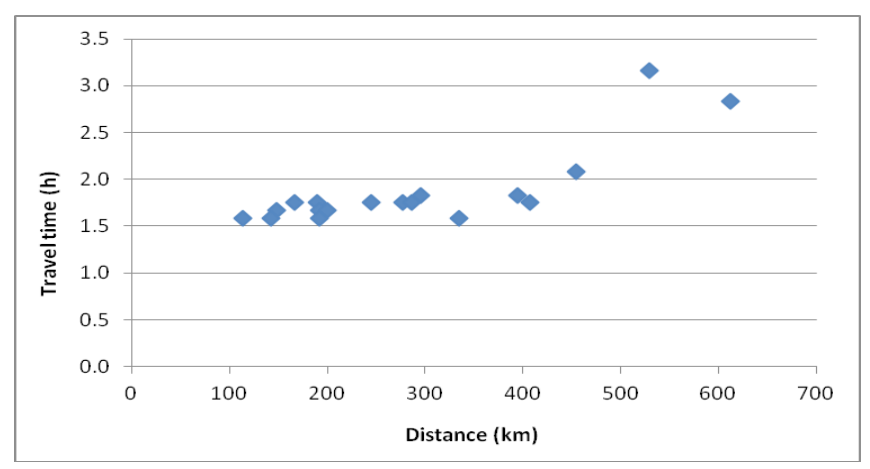

Fig. 6.

Ratio of Travel Time and Distance on Available Air Transport Connections among SEETO Comprehensive Network Airports

Source: South East Europe Transport Information System (SEETIS) III 
Lowest distance between of existing air transport connections is $113 \mathrm{~km}$ on a domestic flight between Skopje and Ohrid, followed by domestic connection between Pula and Zadar $(142 \mathrm{~km})$. It should be stated that mentioned connections were of high national interest for development of tourism in Croatia and FYR Macedonia what justifies very small distances.

Passengers travelling by air have to consider fixed time blocks, respecting their duration, mostly set by air transport. One of the major disadvantages of air transport to rail and to some extent to road is the check in time, asking the passengers to be at the airport much sooner before the actual flight. In general, for European airports it is one hour for economy travellers and about 40 minutes for business travellers, depending on the amount of luggage as well (Cokasova, 2003). Travel time used in analysis is calculated as a sum of waiting time at the airport before the flight, flight time and waiting time at the airport after the flight (Fig. 6). Time spent at the SCN airports before and after the flight (45 minutes) is lower in comparison to European airports due to its smaller capacity and volume of traffic.

\section{Comparative Analysis of Air, Rail and Road Transport Accessibility among the SEETO Comprehensive Network Airports}

Out of possible 136 connections among the SCN airports in 2010 all three transport modes services were available on only five connections (Zagreb-Split; Zagreb-Sarajevo; Belgrade-Podgorica; Belgrade-Skopje and Belgrade-Sarajevo). Those connections were used in the provided comparative analysis (Fig. 7).
Modal shift in passenger transport, additionally accentuated by establishment of high speed rail (HRS) transport, has been extensively evaluated worldwide especially focusing on its impact on air transport demand. That analyse is not directly applicable on the SCN as it includes only conventional railways but it is used for derivation of passenger transport demand common indicator. Travel time is the most significant factor of influence which in the main aspect is determining air/rail/road market share. Travel time has been analysed in correlation to transport price which is defined as second most important factor of influence on passenger choice. However, since among SCN airports only road transport is available on all 136 connections (2010) while rail and air transport is available on respectively 65 and 18 connections, it should be taken into account that passengers are given reduced choices of available transport services.

The EU transport study that examined interactions between HSR and passenger air transport stated that shortening of travel time of $7 \mathrm{~h} 20$ before the opening of HSR transport to $4 \mathrm{~h} 50$ which influenced the travellers to change the mode. In spite further shortenings of travel time to 4h10 many passengers choose again the air transport mode. The investigation of modal shifts on 25 city-pairs has shown that a change in modal choice took place where scheduled rail travel time is less than 3-3h30 hours and for business 2 hours. The same principle can be applied on road transport given that most people preferred to drive than fly on journeys of $300 \mathrm{~km}$ or less (3 hours equivalent travel time) with cost and convenience being major factors (Bureau of Transport and Regional Economics, 2003). 


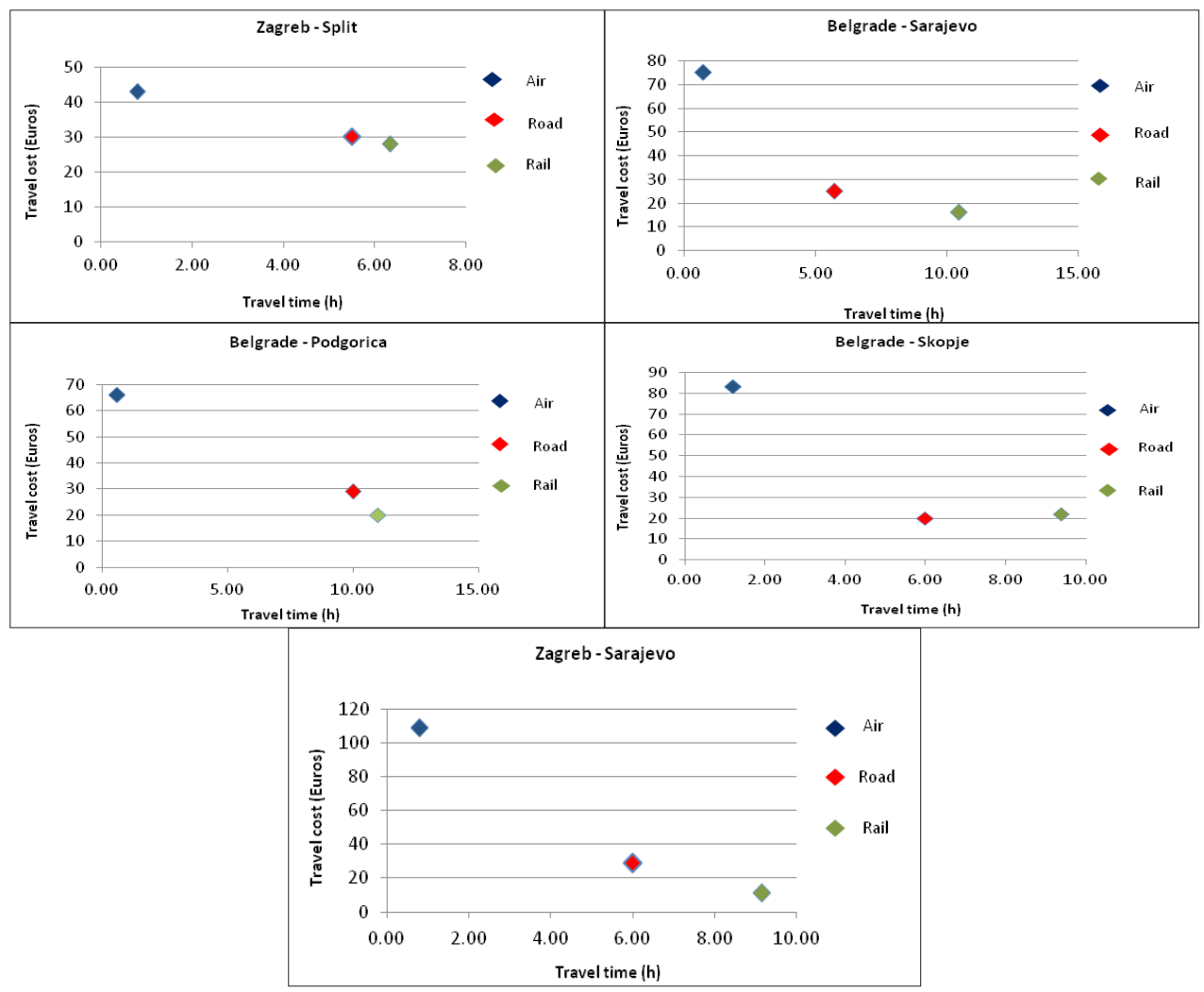

Fig. 7.

Ratio of Travel Time and Cost on Five Sample Connections among SCN Airports Source: Official Airline Guide (OAG) Database

In the SEE 18 road connections have travel distance lower than 3 hours, while only one rail connection is in the same category. It is supported by the fact that 28 road connections have travel distance higher than $800 \mathrm{~km}$ out of which one scheduled (ZagrebSkopje) and one seasonal scheduled air transport connection (Dubrovnik-Belgrade) are operable. Out of 28 road connections with travel distance higher than $800 \mathrm{~km}$, 11 connections have road network length higher that $1000 \mathrm{~km}$ which does not serve for passenger transport.
When elaborating external costs of air, road and rail transport, with $93 \%$ in the EU, road transport is responsible for the lion share of the external costs, aviation (only intra-EU flights are included) has the second largest share in external costs with about $5 \%$ while rail transport is responsible for less than 2\% (CE Delft, INFRAS and Fraunhofer ISI, 2011).

But when comparing travel costs of road, rail and air transport, air fare outpaces road $(+129 \%)$ and rail (+57\%) transport in terms 
of overall cost advantages in operations, infrastructure, cost of utilisation, external environmental and accident costs, starting from a distance of 400 to $500 \mathrm{~km}$ and up as presented (Fig. 8). Already starting from the routes of $500 \mathrm{~km}$ and beyond, travel by air, including environmental costs, is more cost-efficient than road or rail. Aspects such as infrastructure, accidents, environmental costs, operational costs, and the cost of utilisation were taken into account in the overall analysis. It supports the action stated in the White Paper 2011 which requires tripling the length of the existing HSR network in order to transfer majority of medium-distance passenger transport from air to rail by 2050 .

When comparing air, rail and road transport services on five connections among six SCN airports it can be observed that travel time by air is 6.5 times lower than road transport while the travel cost is 3.6 times higher. Even greater difference in proportion of travel time and cost is apparent in comparison of air and rail transport where air travel time is 10.6 times lower and travel cost 5.4 higher than rail transport.

Among observed connections, largest difference in travel times is apparent between rail and air on Belgrade-Sarajevo connection where it takes 9.73 hours longer to travel with rail than with air. Even though average difference between air and road transport travel time is significantly lower than between air and rail travel times, still largest difference between air and road (9.4 hours on Belgrade-Podgorica connection) is almost the same as between air and rail.

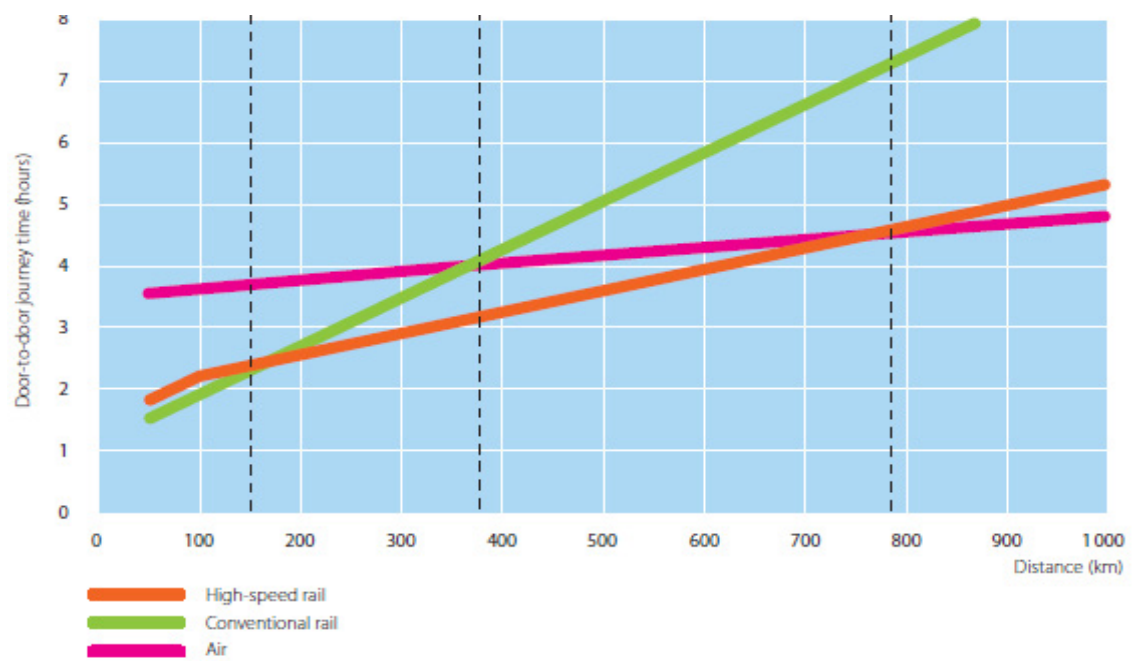

Fig. 8.

Competitiveness of Air and Rail Based on Travel Time

Source: Steiner (2012) 


\section{Conclusion}

Underdevelopment of inland transport infrastructure in the SEE argues an assumption that the air transport is the primary mean in a view of transport intraregional integration and future integration in the TEN-T. It is confirmed by the fact that out of possible 136 connections among the SCN airports, travel time lower than three hours is identified on 18 road connections and one rail connection, while average travel time on rail connections is $\mathbf{1 8}$ hours and on road connections 6.5 hours. Additionally, out of 28 road connections with travel distance higher than $800 \mathrm{~km}$, 11 connections have road network length higher than 1,000 $\mathrm{km}$ which does not serve for passenger transport in the SEE region. However, the stumbling block in the further recognition of SCN airports in relation to the inland transport modes are airport connections with other transport modes and with city centres. In 2010, 18 air transport connections were operable making $13 \%$ out of possible connections in the SEE (136).

In the Western Balkans, regional transport cooperation is dealt with within the framework of the South East Europe Transport Observatory (SEETO). SEETO has defined a regional transport network, and it identifies priority projects of regional interest in a multi annual plan on a rolling basis and follows up transport policy measures.

SEE region, concerning air transport, is a modest, undeveloped region. Intercontinental transport was very significant in JAT's operations in year 1989 and today apart from middle range, routs to Middle East and North Africa does not exist from the SCN airports (Krstić and Stepanović, 2004). The densest routes are international, mainly to and from European Union, due to relatively small SEE countries areas, which implicate lack of domestic traffic with exceptions in Croatia and Serbia. That fact highlights the importance of cross border international traffic on regional and European level. After signing the ECAA agreement liberalisation of air service occurred and the route network has grown rapidly. New established routes are connecting European destinations with SEE region serving neighbouring hub airports as feeders while main regional airport which could compare to European hubs has not yet been established (Steiner et al., 2008). Main airports offering connecting flights are Belgrade and Zagreb although with 3.1 and 2.3 million passengers in 2011 remain small by European standards.

It can be concluded that the air transport in the Western Balkans is evolving from year to year by application of EU legislation. However, the problem of intraregional connectivity prevails, where majority of destinations from and to the SEETO Comprehensive Network airports are in the Western Europe and minor of all air transport operations in the region are realised within the SEE network. Underdeveloped connections between the SEE capitals and major cities represent a barrier for fast and convenient travel within the region. New air links within the SEE region could considerably improve mobility and accelerate economic integration and cooperation processes. In that respect, this new mobility potential should be further considered and analyzed to determine whether a new optimized air transport network could be established.

Innovative solution can be European Personal Air Transport System (EPATS) 
as personal air transport system, driven by personal needs, preference and resources of the population, improving current accessibility, with economic efficiency and ecological sustainability, and within 20 years time horizon.

Around 2,500 landing facilities exist in Europe, with different infrastructure quality (accessibility). ATM reformation need to discuss EPATS demand within the Single European Sky (SESAR research), as well as new technology and operations models. Only 5\% of European population lives in a distance of $40 \mathrm{~km}$ of the nearest HUB, and around $95 \%$ of European population lives in a distance of $40 \mathrm{~km}$ of the nearest GA airport.

As conclusion:

- New air connections within the SEE region could considerably improve mobility and accelerate economic integrations and cooperation processes.

- Small aircraft transport system in Europe/Danube Region/SEE is a solution to improve transport infrastructure (accessibility).

- GA revitalization in Europe needs cooperation and support from ACARE, SESAR, FP7/Horizon 2020 funding.

Accordingly, new air transport connections within the SEE region could considerably improve mobility and accelerate economic integrations and cooperation processes. In that respect, this new mobility potential should be further considered and analysed to answer whether a new optimised route network could be established.

\section{References}

Bureau of Transport and Regional Economics, Working Paper 51. 2003. Regional Public Transport in Australia: Long Distance Services, Trends and Projections.

CE Delft; INFRAS; Fraunhofer ISI. 2011. External Costs of Transport in Europe, Update Study for 2008 Report, Delft, CE Delft.

Cokasova, A. 2003. Air-Rail Inter-modality from Passenger Perspective, EUROCONTROL Research \& Development Center.

Krstić, B.; Stepanović, Lj. 2004. Avio-saobraćaj u turbulencijama, neki elementi za formiranje vazduhoplovne politike (in Serbian), Centar za liberalno-demokratske studije, Belgrade, Serbia.

Mantecchini, L.; Gualandi, N.; Paganelli, F. 2013. Integration and Concentration of European Air Transport Market, International Journal for Traffic and Transport Engineering. DOI: http://dx.doi.org/10.7708/ ijtte.2013.3(2).08, 3(2): 204-219.

Monsalve, C. 2011. Railway Reform in South East Europe and Turkey - On the right track?, The World Bank.

Nikolić, N.; Šimecki, A.; Begović, N. 2008. Valorisation of the SEETO Comprehensive Road Network. In Proceedings of the Third Road Congress, The Association of Consulting Engineers of Bosnia and Herzegovina, Sarajevo, Bosnia and Herzegovina.

Šimecki, A.; Nikolić, N.; Steiner, S. 2011. Valorisation of Air Transport Infrastructure in South East Europe. In Proceedings of the $14^{\text {th }}$ International Conference on Transport Science ICTS 2011, University of Ljubljana, Faculty of Maritime Studies and Transport, Portorož, 1-9.

Steiner, S. 2012. Challenges and solutions for Air transport in the Danube region, The Danube Region Transport Days, Ljubljana, Slovenia. 
Steiner, S.; Božičević, A.; Mihetec, T. 2008.

Determinants of European Air Traffic Development, Transport Problems, International Scientific Journal, 3(4): 73-84.

Steiner, S.; Mihetec, T.; Božičević, A. 2010a. Prospects of Air Traffic Management in South Eastern Europe, Promet - Traffic \& Transportation, 22(4): 293-302.

Steiner, S.; Tatalović, M.; Bajić, J. 2010b. Competition and Cooperation on European Southeast Air Transport Market. In Research Monograph: Economic integrations, competition and cooperation, University of Rijeka, Croatia, 534-552. 